\title{
Botulinum Toxin Type A
}

National Cancer Institute

\section{Source}

National Cancer Institute. Botulinum Toxin Type A. NCI Thesaurus. Code C82623.

An injectable formulation of a neurotoxin derived through the fermentation of the Hall strain of Clostridium botulinum type A with neuromuscular transmission inhibitory and analgesic activities. Upon injection into the affected muscle, the heavy chain portion of botulinum toxin type A (BTX-A) binds to the cell membrane of the motor nerve and is internalized via endocytosis. Upon entry, the light chain portion of the toxin is activated and cleaves the protein SNAP-25, thereby preventing the fusion of acetylcholine (ACh)containing synaptic vesicles with the cell membrane and, so, the release of ACh into the neuromuscular junction; subsequent binding of $\mathrm{ACH}$ to motor end-plate nicotinic acid receptors and ACh-mediated muscle contraction are thus blocked. In addition to ACh, BTX-A may inhibit the release of neuropeptides, such as substance P and glutamate, which may contribute to its analgesic activity. 